\title{
Sisebuto \\ de Toledo
}

Vida y pasión de

San Desiderio,

escrita por el rey

Sisebuto

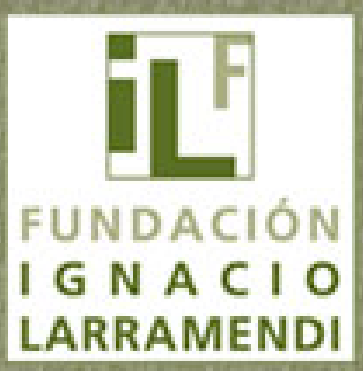

Biblioteca Virtual Ignacio Larramendi de Polígrafos 


\section{ESTUDIO CRÍTICO FHL}

(C) Del texto: el traductor.

(C) De la edición: Fundación Ignacio Larramendi.

Madrid, 2011.

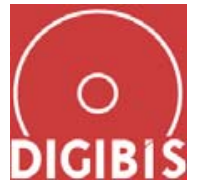

Es una edición electrónica de DIGIBÍS. 


\section{SIGLO VII}

SiSEBUTO De TOLEDO : Vita uel passio sancti Desiderii

Traducción: José Carlos Martín Iglesias

\section{VIDA Y PASSIÓN DE SAN DESIDERIO, ESCRITA POR EL REY SISEBUTO.}

1. Para que sea un modelo para los presentes, para que sirva de edificación a las generaciones venideras, para que estimule el celo religioso de los tiempos por venir me he decidido a escribir la vida de San Desiderio, mártir; y lo que una tradición digna de crédito nos ha dado a conocer, más con un estilo seco que sobrecargado de expresiones ornamentales, lo he dado a conocer, suplicando al Señor, que ha de venir, que nos asista en esto: que él, que dio a aquél, y no inmerecidamente, poder para obrar milagros, disipando el embotamiento de nuestra mente y nuestra lengua, nos dé a nosotros, a pesar de ser indignos de ello, capacidad para exponer ordenadamente lo acontecido.

2. Este varón nacido de padres romanos y consagrado a Dios desde su cuna misma, era de ilustre linaje y pertenecía a una familia nobilísima. Después que alcanzó los años legítimos en que es lícito recibir la enseñanza, es puesto a estudiar. Y sin gran demora, aventajando inmediatamente a los sabios gracias al vigor de su inteligencia, con una completísima instrucción gramatical comenzó a leer las autoridades bíblicas, reteniéndolas con admirable rapidez. Fue, en efecto, por su aptitud infatigable, por su capacidad de recordar memorioso, por su carácter activísimo, por su elocuencia ilustrísimo, y lo que es más importante que todo esto, se mostró lleno de compunción en todas sus acciones: de acuerdo con los Evangelios, proporcionó comida al hambriento y bebida al sediento, ofreció consuelo al enfermo y al preso, y hospitalidad al peregrino, dio ropa al desnudo. No lo ensoberbeció la arrogancia, enemiga de todas las virtudes, no lo incapacitó una lánguida embriaguez, no lo embotó el exceso en la comida, no lo corrompió un voraz desenfreno sexual, no lo cambió la engañosa mentira, no lo sedujo un ansia nociva de riquezas. Y como gracias al favor divino estuvo lleno de tales virtudes $y$, tras franquear la meta de la época de la adolescencia, durante sus años juveniles no se entregó a los placeres, al correrse la voz, se extendió la fama de su bondad, y resplandeció en muchas regiones la obra de la luz, concedida por la verdadera luz. 
3. En fin, los habitantes de muchas ciudades lo reclamaron para sí como santo obispo con el propósito de obtener sus favores, pero él se resistía y se confesaba, como es propio del humilde, inferior a otros e indigno de tan gran cargo. Finalmente, no tanto voluntariamente, como empujado por muchas súplicas, lo ganó como obispo la Iglesia de Vienne, según era el gran deseo de ésta. Tras hacerse cargo de ella, con una predicación prudentísima alejó de la cólera al atrabiliario, de la mentira al falaz, de la rapacidad al codicioso, de los excesos al libidinoso. La embriaguez la domó completamente mediante la sobriedad, de la gula triunfó con la continencia, la discordia la venció con el don de la caridad, la soberbia la detuvo con una sincera humildad, el perezosísimo embotamiento lo arrancó mediante la diligencia. Enseñó a todos a mostrarse generosos con buenas limosnas, compungidos en la oración, firmes en la amistad, perspicaces a la hora de emitir juicios, siempre y en cualquier acción discretos. Y todo esto lo enseñó con el ejemplo más que con palabras, sabiendo que el Señor, que ha de venir, no va a buscar tanto palabras, como obras.

4. Mientras todo esto sucede por la gracia de Cristo, el enemigo de los que se convierten y el aliado de los malvados, el inventor y amigo de la muerte comenzó a gemir y, ceñido de toda clase de armas, se lanzó a luchar él en persona contra el soldado de Cristo. En nada, ciertamente, la astucia del adversario se impuso, en nada su perniciosa maldad quebrantó al varón de Dios, a quien la gracia del Redentor armó con armas espirituales. Finalmente, el espíritu maligno inficionó con su veneno de serpiente a cierto hombre de mente pestífera y, como si se tratase de un brebaje envenenado, introdujo en las entrañas de éste preparativos de acusaciones para que, vomitándolas, su vil boca, a la que alimentó con malignos sentimientos, infamase al atleta de Dios. Persuadió por su propia iniciativa a unos de su misma calaña y preparó contra el siervo de Dios falsamente tales engaños: en efecto, durante el reinado de Teodorico, hombre digno de toda necedad, y de Brunequilda, la favorecedora de las peores prácticas, la más íntima amiga de los malvados, se reúnen con una mujer casada que era de noble linaje, pero de infame carácter, Justa de nombre y detestable en sus acciones, con honor en su nombre, pero más deshonra en su proceder, carente de buenas cualidades y excesivamente cargada de malas, desconocedora de la verdad y nunca ajena al crimen. Ésta, tras ser aleccionada, se quejó en un concilio de haber sido violada en una ocasión por el santísimo Desiderio, ante la extrañeza general de que el siervo de Dios se viese implicado en algo semejante por una acusación; se pensaba más bien que eran invenciones lo que se arrojaba contra él. Pero los presidentes, de acuerdo con las 
maquinaciones preparadas de antemano, con irreflexiva imprudencia dictaron contra el inocente una sentencia injusta e inmediatamente, para castigarlo, lo enviaron privado de su honor al exilio a un monasterio en una isla. Su caída fue su mayor ventura, la afrenta que sufrió su más insigne santidad, su degradación su eterna ventura. Es designado en su sustitución un falso sacerdote de nombre Domnolo, ciertamente un siervo del diablo, y cuanto mayor prestigio alcanzaba el varón de Dios por sus abundantes virtudes, por el contrario aquél se ensuciaba más con actos abominables.

5. En efecto, cuando en este monasterio vivía el santo mártir una vida santa, se presentó pidiendo limosna un pobre cuya boca había cerrado desde su nacimiento el silencio y a quien una perpetua mudez impedía articular su voz. A éste, el Padre Omnipotente, sin desatender la súplica de su soldado, le proporcionó esa gracia y lo capacitó para hablar. Este milagro que aconteció, al correrse la voz, la fama de su bondad no pudo silenciarlo, sino que más bien, recorriendo el mundo entero, lo llevó a conocimiento de muchos, por lo que sucedió que, por la esperanza de recuperar la salud, acudió ante él una gran multitud de enfermos, y no faltó el favor del Señor para sanar a aquéllos por los que el siervo de Dios oró al Señor, nuestro salvador.

6. Suficiente divulgación ha tenido, en mi opinión, la gracia de sus curaciones en las conversaciones cotidianas, pero para no cerrar la puerta a los que gustan de conocer las cosas con detalle atendiendo a una excesiva brevedad, he puesto un especial interés en recoger en esta obra de cualquier modo que he podido algunos ejemplos. Unos ancianos vivían una vida de oscuridad sin luz en sus rostros y rodeados en todo momento de tinieblas, a éstos el soldado del Señor, tras retirar el horrendo velo de sus tinieblas, merced a la gracia de Dios con su oración los devolvió a la anhelada luz resplandeciente.

7. Después de tales sucesos, tres leprosos oprimidos por la angustia de esta enfermedad acudieron ante él para ser curados. Había invadido sus cuerpos una espantosa blancura y las heridas de sus cicatrices cubrían los miembros de los desdichados. Su hedor era insoportable, y larga y abundantemente horrible el aspecto lleno de nudos de su figura, supuraba en él un líquido amarillento y además casi todo su cabello una infección purulenta lo había arrancado espantosamente de raíz tras la pérdida del pelo. El siervo de Dios alejó estos malsanos sufrimientos de los que los padecían y les devolvió la salud dejándolos sanos y alegres.

8. Mientras el Señor con esa acostumbrada piedad suya se mostraba como su garante, el rumor popular llevó a oídos de Teodorico y de Brunequilda que el siervo de 
Dios era exaltado con extraordinarias virtudes y que con el presente de un poder omnímodo le había sido concedido además el don de la curación. Inquietos al punto y convulsionados por el mayor temor, consideran primero detenidamente tan grandes sucesos y se preguntan hasta qué punto se debe devolver al expulsado el honor debido o prolongar la permanencia en el exilio al castigado en vano. Y cuando una artera investigación comenzó ruinmente a indagar la causa de todo el misterio, la venganza divina y no inmerecidamente digna de él se apoderó del inventor de la brujería de la abominable resolución, el que antes se vio que había buscado la condena del soldado de Cristo. Del espantoso fin de éste he dejado constancia en un relato completo describiéndolo con mi cálamo. Esta pestilencial persona y digna de infeliz recuerdo estaba dominada por muchos vicios y crímenes. No obstante, entre las abominables bajezas fueron propias de él el ansia de riquezas y la calumnia, lo que empujó a una grandísima parte del pueblo a matar a este monstruoso oprobio. En efecto, en cierta ocasión en que estaba a la vista de su protector Teodorico es sorprendido por una muerte tumultuosa a manos de los burgundios y su cadáver es abandonado desgarrado por todas partes y ensangrentado. De tal modo perdió el desdichado al mismo tiempo la vida y su espantosa alma y se introdujo a sí mismo voluntariamente en las mazmorras infernales para perecer.

9. ¿Qué puedo decir de aquélla cuyo injusto nombre era Justa y que en justicia habría debido llamarse Injusta, de la que se apoderó el Cruel así como de una posesión propia? Por la misma época en que fue asesinado, como se merecía, el recordado ya antes, también a ella la invadió, como se merecía, un espíritu maligno y toda la abundancia de falsedades que tiempo atrás había preparado la expulsó a su vez completamente fuera lo mismo que se expulsa a un esclavo funesto de la casa. Su forzada confesión fue la siguiente: "Reconozco la falsedad de la acusación tramada contra el siervo de Dios, juzgo el pleito, comprendo también, y es de lo que más consciente soy, la pena que se debe pagar. Que de esto el Omnipotente Vengador haga responsable a Brunequilda, que lo tramó, que estas penas las vuelva contra ella, que sobre ella haga recaer los sufrimientos del tormento su diestra vengadora, sobre ella cuya vana persuasión me ha arrastrado a la perdición, un servicio éste digno de ser maldecido hasta la muerte, una promesa que ha de perecer sin proporcionar ningún beneficio”. Y cuando puso fin a sus palabras, el artífice de todos los vicios la hizo perecer muerta por asfixia y la arrastró consigo hasta las ardientes llamas vengadoras donde habrá de arder por siempre. 
10. Al enterarse de las muertes de los antedichos, Brunequilda y Teodorico se asustaron. Al considerar que tales sucesos se habían producido por juicio divino se aterrorizaron todavía más y para no ser castigados con una idéntica pena, fingiendo compasión, dan instrucciones para que el varón de Dios, que había sido expulsado en vano de su obispado, se presente de nuevo para dirigir su Iglesia, como era vivamente deseado. Al negarse éste a lo que se le solicitaba y afirmar que iba a permanecer donde había sido desterrado, le pidieron con repetidas súplicas que no les negase su presencia y que perdonase con talante clemente los engaños que habían perpetrado. Una sincera piedad ablandó, efectivamente, su sincero corazón, y una abundante clemencia abrió al siervo de Dios el camino del regreso. Y cuando este mismo santísimo varón llegó a presencia de los dos malvados, se apresuran a caer postrados a sus pies, y se esforzaban por ganarse su favor después de que tiempo atrás lo habían desterrado con un castigo basado en falsedades, y para que la reparación de tan gran impiedad los liberase del castigo, pues se habían visto implicados en las acusaciones por una funesta influencia. Aquél, por su parte, perdonó con talante clemente el crimen perpetrado contra él, y de acuerdo con el dicho del Señor no conservó recuerdo de las culpas de sus deudores, sino que las olvidó.

11. Inmediatamente la Iglesia de Vienne, tras la expulsión de Domnolo en penosas circunstancias, acogió exultante a su guía en medio de la mayor concurrencia. Se alegraban de que el enfermo hubiese encontrado médico, de que el oprimido hubiese hallado consuelo, de que el necesitado tuviese ya alimento: ¿qué decir de muchos otros beneficios? Fueron reportadas por el Señor a la Iglesia de Vienne abundantes mercedes: en efecto, a la penuria causada por diversas calamidades, a las numerosas mortandades que ocasionaba la peste, a las desmesuradas tormentas que se abatían sobre la ciudad puso fin la presencia del santo varón gracias a la misericordia del Señor. Éstas, sin duda, al ser alejado el pastor, las provocó su ausencia.

12. En fin, por más que mi desaliñada prosa carezca de elegancia, he decidido contar tres milagros de éste. Cuando en cierta ocasión acudió ante él a visitarlo una gran cantidad de gente, y según la costumbre mandó que la atendiesen con comida y bebida, le fue comunicado por un sirviente que faltaba vino del tipo más deseado. Ordenó rápidamente que le fuese mostrada la vasija donde tal líquido ya se había terminado, ésta al recibir sobre sí la señal de la cruz se llenó de nuevo por la gracia del Salvador con el excelente y aromático vino. Así, el gentío que acudió fue reconfortado al mismo tiempo con una bendición y una bebida consagrada. 
13. Cuando en otra ocasión mortificaba su cuerpo con el ayuno en medio de un prolongado retiro y llevaba ya un tiempo absteniéndose del consumo de carne, no porque fuese inmundo, sino buscando la templanza, acudió junto a él a visitarlo no lejos de la ciudad otro sacerdote. Se daba entre ellos una amistosa conversación sobre las señales divinas entre otros temas, y he aquí que, cuando Febo en su recorrido de los espacios diurnos había sobrepasado el eje del mundo y se acercaba el momento conveniente de la comida, súbitamente, cortando el aire, mientras sus plumas crepitaban en rápido vuelo, apareció en medio del refulgente cielo un águila, la reina de las aves, la cual, llevando un pez, arrojó ante sus rostros el animal marino, que éstos tomaron prosternándose llenos de gozo y recibiéndolo con la mayor alegría y dando gracias a la generosidad del Señor.

14. Algún tiempo antes de los sucesos de su noble pasión sucedió que llenando un candil con sus propias manos lo encendió junto al altar, éste irradia a lo lejos alargados haces de luz y creciendo sin añadirle nada más sobrepasa la medida de su capacidad. En efecto, el aceite que sobra es recogido con la mayor veneración y expulsa por la gracia de Dios enfermedades y dolores y aleja los sufrimientos malsanos que padecen los hombres proporcionándoles salud. Sobre la vida de éste baste haber dicho esto que mi pobre prosa ha podido resumir en sus puntos esenciales.

15. Ahora sobre su pasión, sobre cómo entregó su santa alma al Señor Todopoderoso, voy a hacer una exposición con la ayuda de Dios según ha llegado a nuestro conocimiento. Como se veía que tanto Teodorico como Brunequilda por sus odiosos vicios no suponían un beneficio, sino un perjuicio, y más bien causaban la ruina que reinaban y, entregándose a la ruina del perjurio y faltando con mente sacrílega a las promesas de su juramento, llenos de perfidia se dirigían a su perdición, y como no les quedaba ningún tipo de infamia o crimen por cometer, a causa de estos males el mártir de Dios, su inspector y pontífice, según su costumbre, ciertamente, levantó su voz semejante al resonar profético de una trompeta y se entregó por entero a erradicar las faltas de éstos para acercar a Dios a aquéllos a los que el diablo había alejado, recordando aquella frase de las Sagradas Escrituras: “El que convierte a un impío salva el alma de éste y disimulará la multitud de sus propios pecados”. Pero los vasos de la ira, el pábulo de los vicios y el arbusto de la condenación le correspondieron con amarguras en pago a su dulzura, con asperezas en pago a su ternura, en pago a la salud que intentaba otorgarles con ungüentos mortíferos. Y el cruel enemigo asediaba el corazón de éstos y los tenía cautivos bajo su poder la astutísima serpiente, y no podían 
alcanzar libremente por su propio pie el puerto de la salvación dado que el funesto saqueador los había sujetado con cadenas especialmente macizas. Saciados con los mortíferos brebajes de éste, comenzaron a lanzar iracundos ladridos contra el siervo de Dios y con sonoros términos a vomitar amenazantemente inmundísimas palabras. Pero ni la amenaza de unos mortales quebrantó al mártir de Dios, ni la ira de unos perjuros lo aplacó, ni la tempestad de unos insensatos lo doblegó: se mostró firme en medio de las persecuciones a pesar de que había de ser maltratado por causa de su probidad, hasta obtener el reino celestial prometido por el Señor.

16. El Enemigo, al contemplar la intachable firmeza de este hombre, se agitó todo él en los corazones de Brunequilda y Teodorico, que nunca abandonó, como si estuviese en su propia morada, y de modo imperativo los empujó más hacia su propia perdición, una deuda que tenían con él, prometiendo otorgarles el primer lugar a la hora de los tormentos en caso de que pudiesen arrancar el alma del soldado de Cristo de las cadenas corporales. Inmediatamente, con funestas palabras su boca sacrílega y siempre bien pertrechada tratándose de invectivas ladró una sentencia de linaje impío: "Es nuestra decisión que Desiderio, hostil a nuestras costumbres y enemigo de nuestros actos, sea castigado a ser lapidado y sometido a todo tipo de penas”. Rápidamente sus esbirros, cómplices en el crimen, dispuestos a cumplir malvadamente el edicto de este mandato tan abominable que con sus oídos toman vilmente del que así lo ordena, hacen esta promesa. Pero no se le ocultaban al mártir de Dios los combates que había de librar en su tarea, siendo así que había sido predestinado por el Señor, es más, advertido de ello por éste, para obtener el premio de la corona.

17. Éste, cuando advierte que ha llegado el día esperado, súbitamente es arrancado del seno de su iglesia a manos de los impíos de forma precipitada y, como un reo que hubiese de ser ejecutado, aunque inocente, es conducido al suplicio. Era enorme e insoportable el llanto del pueblo: carecían de remedio al serles suprimido el de tan gran pastor, y clamaban con estas palabras: “¿Por qué padre piadoso abandonas tu redil? ¿Por qué dejas a tu rebaño siendo así que éste ha de perecer? ¡No nos arrojes, te lo suplicamos, en las fauces de los lobos!, ique tus ovejas, reconfortadas hasta este momento suavemente con flores cargadas de néctar, no seamos desgarradas por punzantes abrojos y ganchudos espinos al no dedicarnos tus cuidados como pontífice! Es sin duda cierto, y nuestras palabras concuerdan con las Sagradas Escrituras, que la ausencia del pastor supone la dispersión de las ovejas, y la presencia de aquél el mayor beneficio de éstas. Ninguna razón hay para que suframos el que nos seas arrebatado. Por 
ello, si se nos niega disfrutar la vida deseada, que se nos permita afrontar junto a ti una muerte gloriosa”. Finalmente, el santo mártir contestó serenamente a estas palabras del siguiente modo: "Una intención, ciertamente, digna de ser admirada, pero no una devoción digna de ser alabada. Si nos cercasen las infernales puertas de la caverna, si los siniestros infiernos intentasen cerrar sus cerrojos, si, crepitando, la horrenda llama del báratro tratase de atacarnos, habría convenido luchar esforzadamente contra el enemigo con las armas espirituales. Ahora bien, puesto que se nos invita a militar en los campamentos celestiales junto con los radiantes escuadrones de los ángeles, con los apóstoles y los varones apostólicos, y con los refulgentes batallones de los mártires, y se nos otorga la vida verdadera en toda su plenitud, permitid, os lo suplico, que vuestro pastor regrese junto al pastor de todos los pastores para que más fácilmente, al marchar por delante su pontífice, el rebaño entero pueda llegar al lugar ya dispuesto”.

18. Así dice, y he aquí que de repente se presenta fuera de sí una apiñada caterva de sicarios furibundos, hombres perversos y de rostro completamente horrible, su frente era ceñuda, sus ojos amenazadores, su aspecto odioso, sus ademanes horrendos. Eran siniestros de mente, depravados de costumbres, falaces de lengua, obscenos en sus palabras, inflados por fuera, vacíos en su interior, en ambos sentidos repugnantes, faltos de buenas cualidades, ricos en las pésimas, entregados a los delitos, enemigos de Dios, amigos absolutamente perpetuos del diablo, excesivamente dispuestos a matar. Esta execrable plaga, dominando sus armas un delirio totalmente infame, agarró violentamente al mártir de Cristo y su rocoso corazón arrojó sobre él una lluvia de piedras. Aunque estos terribles proyectiles de la furibunda tropa pasaban completamente de largo sobre aquél y desviaban su curso hacia otra parte, aunque la durísima naturaleza de las rocas y el fragor mismo de la lapidación mostraban estar al servicio del siervo de Dios, y aunque sin ser seres vivos, no obstante, como seres vivos que viviesen de acuerdo con las leyes divinas cedían ante Dios, sólo el pecho humano permaneció inflexible cuando pudo haberse inclinado igualmente a la conmiseración. Cuando aquél exhalaba su alma, uno, cogiendo una vara, quebró el santo cuello del varón. Así su alma abandonando la materia carnal y despojándose de las cadenas corporales, victoriosa llevó a su compañero hasta el astrífero cielo.

19. La vida y la muerte del soldado de Cristo esta descuidada prosa mía, como ha podido, las ha expuesto a un tiempo, la cual, por más que desagrade en su torpeza a los cultivados por su excesivo desaliño, dejada a un lado la pompa de las palabras, mejora humildemente a los que sienten la fe y creen. Así pues, del mismo modo que 
hemos descrito la vida, los milagros y el fin grandemente glorioso de éste, nos queda por narrar la ruina y la muerte de los depravados. Cuando Teodorico, apartándose de Dios, es más, abandonado por Dios, al recibir la noticia sobre el siervo de Cristo, se mostraba exultante, afectado de disentería perdió su perversísima vida y se ganó como amiga perpetua a la muerte.

20. Perdió todo consuelo la depravada Brunequilda, destinada a la perdición, y llena de temor era atormentada interiormente por su acusadora conciencia preguntándose en qué medida el subsiguiente castigo la reclamaría mortificándola rigurosamente entre tormentos a ella a la que la magnitud de su culpa la hizo destacar en el crimen perpetrado. Mientras daba vueltas a esto en su interior sombríamente, declaró la guerra a un pueblo vecino. Pero cuando llegó el momento de combatir y el apiñado ejército contrario chocó contra el suyo, un terror enviado por Dios invadió al bando de la perversísima mujer, con lo que aconteció que los aturdidos miembros siguieron a la malsana cabeza en busca del refugio de la huida. Así, cuando vagaban sin rumbo ante el rostro de sus enemigos, fue capturada en primer lugar por sus enemigos la enemiga de la doctrina cristiana y la autora de todo tipo de crímenes.

21. Con respecto de la muerte de ésta, no será inoportuno decir lo que hemos conocido al correrse la voz. Hay un animal quebrado que posee además un cuerpo desmesurado y ciertas sinuosidades naturales: la parte superior de su lomo, aunque más bien hinchada y reducida, presenta un lugar más elevado que las restantes articulaciones, larga y abundantemente apropiado para la carga, por lo que es superior a los demás animales a la hora de transportar pesos. La susodicha, después de ser despojada de su ropa, es alzada hasta lo alto del centro de éste y conducida ignominiosamente por delante de los rostros de sus enemigos. Durante largo tiempo proporcionó a los que la contemplaron una visión asombrosa y repugnantísima. A continuación es atada a unos corceles salvajes y arrastrada por lugares impracticables y rocosos. Así, su cuerpo, ya consumido por la vejez, es desgarrado a pedazos por los impetuosos caballos, y sus miembros yacen esparcidos de forma irreconocible por doquier, despedazados y ensangrentados. Liberada de tal modo su alma de la materia carnal y condenada a penas eternas, y no inmerecidamente, es oprimida por sombrías aguas hirvientes de pez donde ha de arder.

22. Esto tuvo una mayor y más extensa continuación por la presencia de otras circunstancias, pero para que no desagrade por su prolijidad a los que se sientan cansados, pongamos término y fin añadiendo a continuación unos breves sucesos dignos 
de ser conocidos, y solicitando a todos en común que no acojan con total indolencia lo que a nuestro Señor Jesucristo no contrarió otorgar a través de su mártir. Tan gran abundancia de curaciones junto al veneradísimo cuerpo de éste ofrece Cristo: cualquiera que esté atormentado por una enfermedad de cualquier tipo o abatido por la debilidad de su cuerpo, tan pronto como suplica allí con todo su corazón al Verbo Divino, alejando de sí todas las enfermedades y expulsando toda imperfección, alcanza sano y feliz la deseada salud por la gracia de Dios, nuestro Señor, que es uno en la Trinidad y existente por siempre, el cual ojalá me otorgue la vida eterna a pesar de que soy completamente indigno de acompañarlo, y a vosotros, los que oís, os conceda su gracia en abundancia.

SE ACABÓ.

[J. C. M.] 